\title{
Investigation on Pile Group Supported Columns
}

\author{
Koppula. Ramkrishna Reddy ${ }^{1}$, Chinnamsetty Ravi ${ }^{2}$ \\ Department of Civil engineering, Mother Teresa Institute of Science and Technology
}

\begin{abstract}
This Paper presents the results of static load tests carried out on a model plane frame with plinth beam founded on pile groups embedded in the cohesion less soil (sand). The response of the structure considered include the displacements, rotations, shear forces and moments in the frame. Comparison of the interactive behavior from the experimental results has been made with the behavior from conventional method. Results revealed that the shear force and bending moment in the frame reduced considerably because of soil interaction. It is also found that, as the rigidity of the plinth beam reduces the shear force and bending moment values from the experimental results have shown considerable reduction. The response of the system from the conventional method of analysis is always on higher side irrespective of level of loading which emphasizes the need for consideration of building frame-pile foundation-soil interaction and reduction of rigidity of plinth beam.
\end{abstract}

Keywords: Phrases: Cohesion less Soil, Soil interaction, Plane building Frame, pile groups;

\section{Introduction}

Pile foundations are generally used to support and transfer heavy loads from super structure to deeper loads bearing stratum. Increasing need of construction of structure like transmission tower, tall chimneys, and jetty structures requires the pile foundations [1,2]. For proper functioning of such structures, two criteria must be satisfied. 1) A pile should be safe against ultimate failure, 2) Normal deflection at working loads should be within the permissible limit [3, $4 \& 5]$. Pile foundations often subjected to following loads

1) Lateral loads due to wind, waves, berthing of ships

2) Heavy compressive loads

3) Uplift and oblique uplifting force

4) Eccentric and inclined loads due to combined action of horizontal and vertical loads and moments.

The nature of the loading and the kind of soil around the pile, are major factors in determining the response of an isolated single pile and the pile groups. The influence caused by the settlement of the supporting ground on the response of framed structures was often ignored in structural design [6]. Soil settlement is a function of the flexural rigidity of the superstructure [7]. The structural stiffness can have a significant influence on the distribution of the column loads and moments transmitted to the foundation of the structure. The effect of interaction between soil and structure can be quite significant $[9,10]$. Interaction analyses have been reported in numerous previous studies such as Meyerhof (1947, 1953), Chamecki (1956), Morris (1966), Lee and Harrison (1970), Lee and Brown (1972), and even a few studies in the recent past such as Deshmukh and Karmarkar (1991), Noorzaei et al. (1995), Srinivasa Rao et al. (1995), Dasgupta et al. (1998) and Mandal et al. (1999). The common practice of obtaining foundation loads from the structural analysis without allowance for foundation settlement may, therefore, result in extra cost that might have been avoided had the effect of soil-structure interaction been taken into account in determining the settlements [11, 12\&13]. This requires that the engineers not only understand the properties of the ground but they also need to know how the building responds to deformation and what the consequences of such deformation will be to the function of the building. In this regard, many analytical works have been reported on the building frames founded on pile groups by Buragohain et al. (1977), Ingle and Chore (2007), Chore and Ingle (2008a, b) and chore et al. (2009, 2010). But no significant light was thrown in the direction of experimental investigation of the effect of soil interaction on building frames founded on pile groups [14, 15\&17].

The aim of this paper is to present the experimental investigation of model plane frame without plinth beam and frame with plinth beam supported by pile groups embedded in cohesion less soil (sand) under the static loads (Central concentrated load, uniformly distributed loads (UDL) and eccentric concentrated load). The need for consideration of soil interaction in the analysis of building frames and the use of plinth beam instead of conventional one is emphasized by comparing the behavior of the frame obtained by the experimental results the conventional method of analysis. An attempt is made to quantify the soil interaction effect and the use of plinth beam on the response of the building frame in terms of displacement, rotations, shears, and bending moments through the experimental investigation. 


\section{Experimental Analysis}

The experimental analysis for static vertical loads on a model building frame without plinth beam, with conventional plinth beam supported by pile groups embedded in cohesion less soil (sand) is presented in this paper. The effect of soil interaction, conventional plinth beam on displacements and rotation at the column base and also the shear and bending moments in the columns of the building frame were investigated. The experimental results have been compared with those obtained from the conventional method of analysis.

Table1: Zone-3, Sand properties (India)

\begin{tabular}{|l|l|}
\hline Angle of Internal Friction & 28 degrees \\
\hline Zone (India) & 3 \\
\hline Relative Density & $31 \%$ \\
\hline Specific Gravity & 2.62 \\
\hline Bulk Density & $1.65 \mathrm{~g} / \mathrm{cc}$ \\
\hline
\end{tabular}

\subsection{Experiment Setup}

Initially the soil is placed in the form of layers. Prior to this work it is required to obtain properties of soil such as Zone, Relative density, Angle of internal friction. Model pile group along with building frame is placed such that it should have a cover of $5 \mathrm{~cm}$. if refers to free standing pile group which is most commonly used in coastal areas. Dial gauges were placed at proper locations by suitable means to determine deformations in vertical and lateral directions.



Figure 2.1: Model plane frame

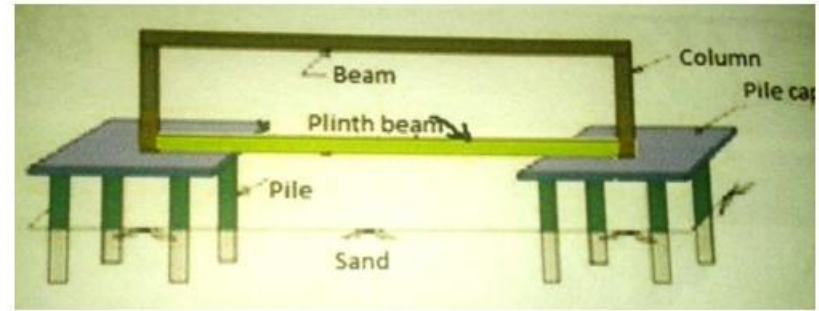

Figure 2.2: Model frame with plinth beam
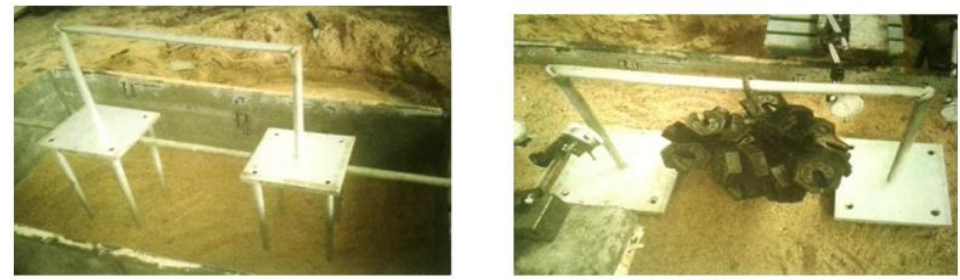

Figure 2.3: Model plane frame at base setup Figure 2.4: Model plane frame at central concentrated load

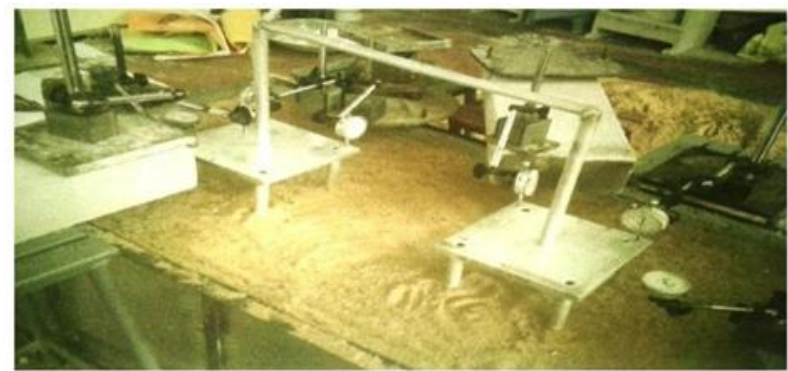

Figure 2.5: Model plane frame arrangement of dial gauge 


\section{Analytical Model}

\subsection{Analysis Programme Using Anasys}

The analysis of the model plane frame is carried out using ANSYS for the following cases

1. With Plinth beam of $3 \mathrm{~mm}$

2. With plinth beam of $5 \mathrm{~mm}$

3. With plinth beam of $6 \mathrm{~mm} \times 6 \mathrm{~mm}$

4. With plinth beam of $8 \mathrm{~mm} \times 8 \mathrm{~mm}$

The above four problems are solved for the following cases: 1) Frame with fixed bases to evaluate the shear force and bending moment in the column, which is the usual practice done known as the conventional method, 2) Back figured values of shear force and bending moment.The finite element tool has the ability to solve the complex problems FEA has a history of being used to solve complex and cost critical problems. In the recent years, FEA has been universally used to solve structural engineering problems. The departments, which are heavily relied on this technology, are the automotive and aerospace industry. Due to the need to meet the extreme demands for faster, stronger, efficient and high rise structures and aircraft, manufacturers have to rely on this technique to stay competitive. There are three approaches to numerical modeling. The finite element, Difference, and Finite volume approaches, the finite element approach is widely popular its generic formulation, a technique that lends itself to commercial code product nodal points and elemental volumes are generally formulated to accommodate of problems. Finite Element Method approach can be used for irritation material advection, thermal diffusion large displacement of solid material. Therefore finite element method is for analysis.

Discretization of the domain: - The task is to divide the continuum under study into a number of subdivisions called element. Based on the continuum it can be divided into line or area or volume elements.

Application of Boundary Conditions: - From the physics of the problem we have to apply the field conditions i.e. loads and constraints, which will help us in solving the problems.

Assembling the system equations: - This involves the formulation of respective characteristic (Stiffness in case of structural), equation of matrices and assembly equations are solved.

Viewing the results:- After the completion of the solution we have to review the required results. The first two steps of the problem is as pre-processing stage, third and fourth is processing stage and final step is known as post-processing stage.

\subsection{Ansys Software}

The ANSYS program has many finite element analysis capabilities, ranging from a simple, linear, static analysis to a complex, nonlinear, transient dynamic analysis. The ANSYS finite element analysis software enable user to perform the following tasks

1. Build computer model or transfer CAD model of structures, products, components of system

2. Apply operating loads or other design performance conditions

3. Study physical responses, such as stress level, temperature distribution, or electromagnetic field

4. Optimize a design early in the development process to produce production costs

The ANSYS program has a comprehensive graphical user interface (GUI) that gives users easy, interactive access to program functions, commands, documentation, and reference material. An intuitive menu system helps users to navigate through the ANSYS program. A typical ANSYS analysis has three distinct steps, ie, Building the model, Apply loads and obtain the solution, and Review the result.

Defining Element Type:- The Ansys Element Library Contain More Than 150 Different Element Types, Each Element Type Has A Unique Number And A Prefix That Identifies The Element Category Such As Beam4, Plane77, Solid96, Etc. Other Element Categories Are Beam, Circuit, Combination, Contact, Fluid, Hf (High Frequency), Hyper Elastic, Infinite, Interface, Link, Mass, Matrix, Mesh, Pipe, Plane, Shell, Solid, Source, Surface, Target, Transducer, User, Viscoelasitic.

Defining Analysis Type and Analysis Options:- The analysis type is chosen based on the loading conditions and the desired response. For example, if natural frequencies and modal shapes area to be calculated, a modal analysis is chosen. The following analysis types can be performed in the ANSYS program: static (or steady state), transient, harmonic, model, spectrum, buckling, and sub structuring. Not all analysis types are valid for all disciplines. Model analysis, for example, is not valid for a thermal model. Analysis options allow the user to customize the analysis type. Typical analysis options are the method of solution, stress stiffening on or off, and Newton-Raphson options. While performing a static or full transient analysis, advantage of the solution control dialog box can be taken to define many options for the analysis. It is necessary to specify either a new analysis or a restart, but a new analysis is the choice in most cases. A single frame restart allows the user to resume a job 
at its end point or about point. Single frame restart is available for static (steady state), harmonic (2D magnetic only), and transient analysis. A multi-frame restart allows the user to restart an analysis at any point. Multiframe restart is available for static or full transient structural analysis. One cannot change the analysis type and analysis options after executing solution. Once the analysis type and analysis options are defined, the next step is to apply loads. Some structural analysis types require other items to be defined first, such as master degrees of freedom and gap conditions.

Applying Loads: - The word loads as used in ANSYS includes boundary conditions (constraints, supports, or boundary field specifications) as well as other externally and internally applied loads. Loads in the ANSYS program are divided into six categories: Most of these loads can be applied either on the solid model (key points, lines, and areas) or the finite element model (nodes and elements). Two important load-related terms are load step and sub step. A load step is simply a configuration of loads for which a solution is obtained. In a structural analysis, for example, wind load may be applied in one load step and gravity in a second load step. Load step are also useful in dividing a transient load history curve into several segments.

Sub step are incremental steps taken within a load step. They are mainly used for accuracy and convergence purposes in transient and nonlinear analyses. Sub steps are also known as time steps - steps taken over a period of time. The ANSYS program uses the concept of time in transient analyses as well as static (or steady-state) analyses. In a transient analyses, time represent actual time, in seconds, minutes, or hours. In a static or steady-state analysis, time acts as a counter to identify load steps and sub steps.

Loading Overview: - The main goal of a finite element analysis is to examine how a structure or component responds to certain loading conditions. Specifying the proper loading conditions is, therefore, a key step in the analysis. Loads on the model can be applied in a variety of ways in the ANASYS program. Also with the help of load step options, user can control how the loads are actually used during solution.

\section{Results And Discussion}

\subsection{Experimental Results}

Using the ANSYS and Finite Element Analysis, the techniques are used to find how a structure responds for different loading conditions.

The salient points that emanate from this study are:

- Figure 4.1 Load vs. Lateral displacement for central concentrated load, shows that for the lower load on the frame linear variation and higher loading shows non linear relation.

- The axial rigidity various from 0 to $4480 \mathrm{KN}$, the actual lateral displacement decreased by $52 \%$.

- Figure 4.2 Load vs. Rotation for central concentrated load, the axial rigidity various from 0 to $4480 \mathrm{KN}$, the settlement decreases by $40 \%$.

- $\quad$ Figure 4.3 Load vs. Lateral displacement for uniform distributed load, the axial rigidity various from 0 to $4480 \mathrm{KN}$, the lateral displacement decreases by $51.01 \%$.

- Figure 4.4 Load vs. Rotation for uniform distributed load, the axial rigidity various from 0 to $4480 \mathrm{KN}$, and the rotation decreases by $39.34 \%$.

\subsection{Analytical Results}

The salient points that emanate from this study are:

- Figure 4.5 Load vs. Shear force for central concentrated load, plot shows that the lower load on the frame follows linear relation and higher loads on the frame it is in non linear relation.

- The axial rigidity various from 0 to $4480 \mathrm{KN}$, and the shear force increased by $12.87 \%$.

- Figure 4.6 Load vs. Bending moment top for central concentrated load, the axial rigidity various from 0 to $4480 \mathrm{KN}$, and the bending moment top increases by $9.27 \%$.

- $\quad$ Figure 4.7 Load vs. Bending moment bottom for central concentrated load, the axial rigidity various from 0 to $4480 \mathrm{KN}$, and shear force increases by $19.52 \%$

- Figure 4.8 Load vs. Shear force for uniform distributed load, the axial rigidity various from 0 to $4480 \mathrm{KN}$, and the shear force increases by $11.39 \%$.

\section{Conclusions}

- The experimental results shows the variation of load vs displacement is nearly liner of loading for higher load on the frame it is nonlinear variation.

- As the axial rigidity of plinth beam increases from 0 to $4480 \mathrm{KN}$, the lateral displacement decrease by $55.88 \%$

- As the axial rigidity of plinth beam increases from 0 to $4480 \mathrm{KN}$, the rotation decreases by $64.12 \%$ 
- As the axial rigidity of plinth beam increases from 0 to $4480 \mathrm{KN}$, the settlement decreases by $54.45 \%$.

- The results show that the lateral displacement, rotation and settlement as the base of the column of a building frame deepens as the axial rigidity of the plinth beam increases.

- As the axial rigidity of plinth beam increases from 0 to $4480 \mathrm{KN}$, the shear force increases by $13.7 \%$.

- As the axial rigidity of plinth beam increases from 0 to $4480 \mathrm{KN}$, the bending moment top increases by $14.19 \%$.

- As the axial rigidity of plinth beam increases from 0 to $4480 \mathrm{KN}$, the bending moment bottom increases by $19.77 \%$.

- Hence the shear force and bending moment in the frame increases so to reduce the effect of rigidity of plinth beam on design parameters- it is suggested that any element which will have less axial rigidity such as geotextiles can be used as plinth beam.

\section{Acknowledgements}

The authors thank the Principal of Amrita Sai Institute of Science and Technology, Paritala, Chanchikacharla and the head of the department of Civil Engineering, for their kind support during the experimental investigation. The authors express their profound thanks to Dr. Sasidhar, Professor, Amrita Sai Institute of Science and Technology for his critical reading and suggestions.


Figure 4.1 Load vs. Lateral displacement for central concentrated load Figure 4.2 Load vs. Rotation for central concentrated load
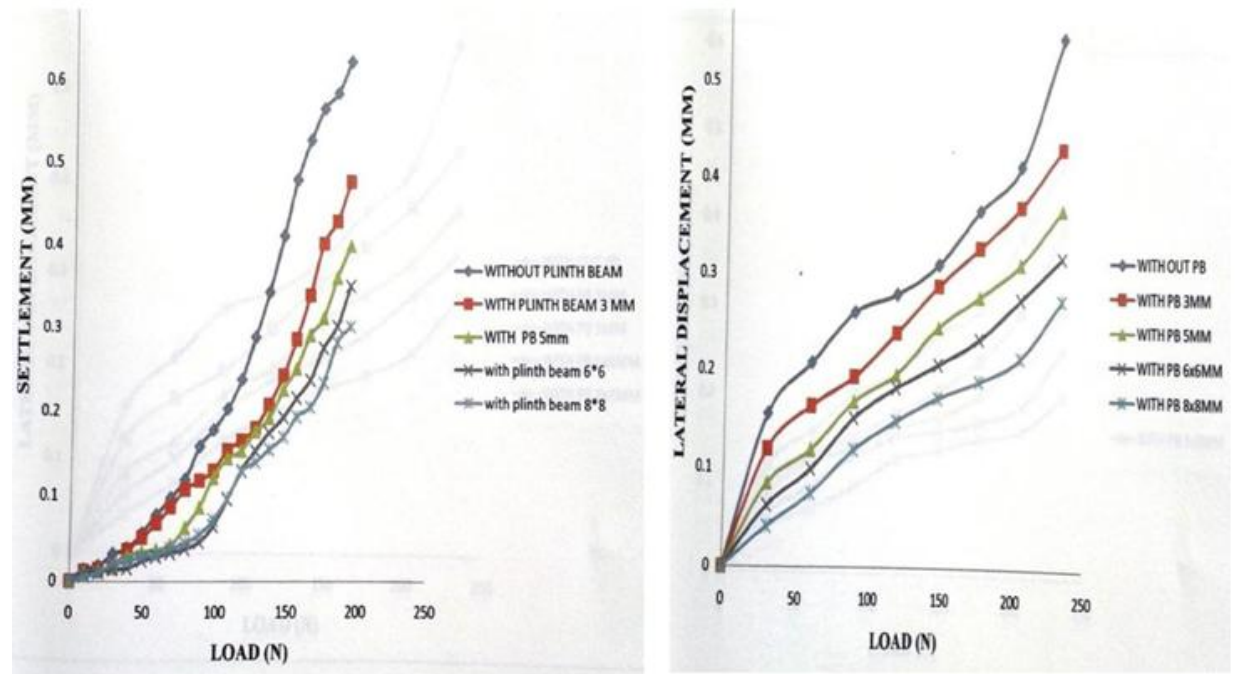

Figure 4.3 Load vs. Lateral displacement for uniform distributed load

Figure 4.4 Load vs. Rotation for uniform distributed load 

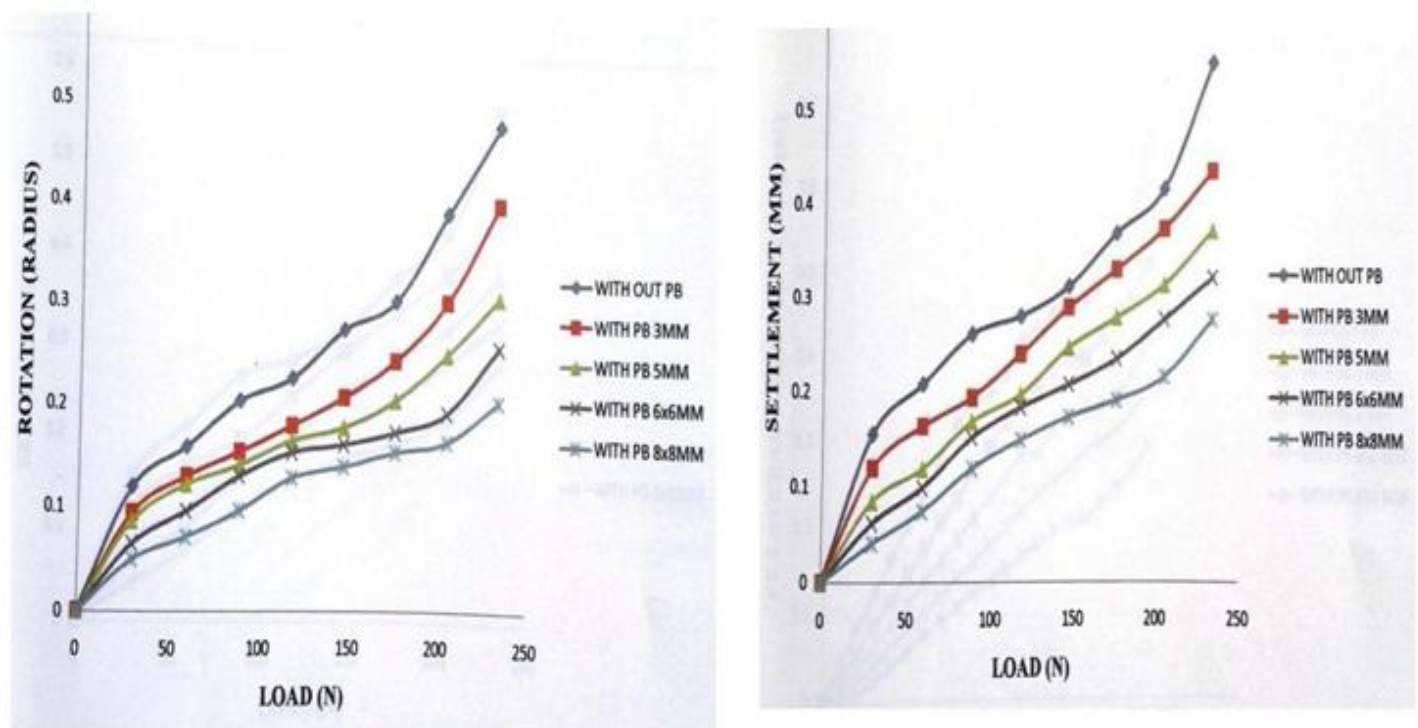

Figure 4.5 Load vs. Shear force for central concentrated load

Figure 4.6 Load vs. Bending moment top for central concentrated load
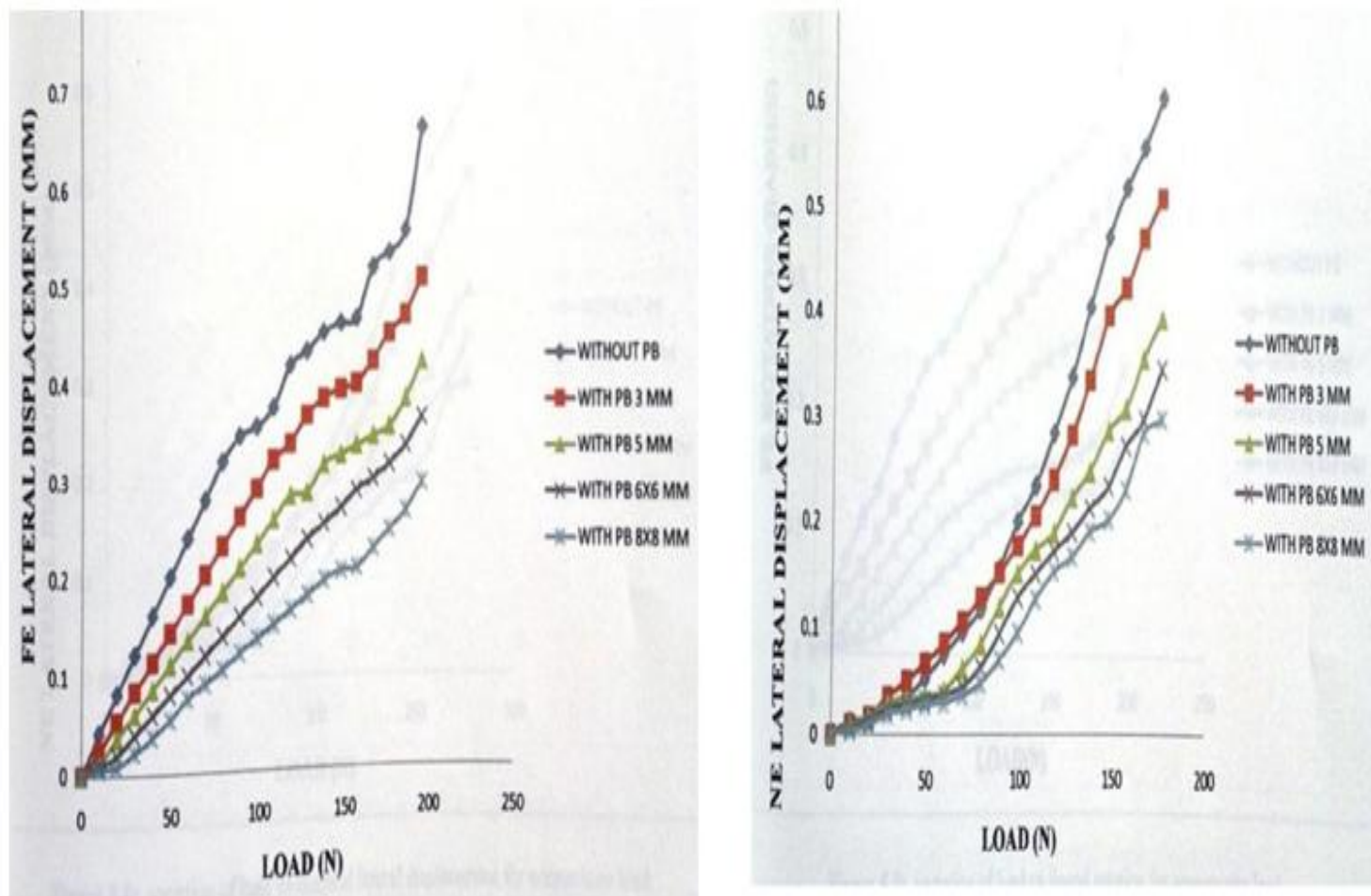

Figure 4.7 Load vs. Bending moment bottom for central concentrated load

Figure 4.8 Load vs. Shear force for uniform distributed load

\section{Reference}

[1]. American petroleum Institute (1987), "Recommended practice for planning, designing, and constructing fixed offshore platforms", API Recommended Practice, 2A (RP-2A), $17^{\text {th }}$ edition.

[2]. Dr. T.D. Gunneswara Rao and C. Ravi Kumar Reddy have done the experimental analysis of building frame pile foundation soil interaction in (2011)

[3]. Basarkar, S.S. and Dewaikar, D.M. (2005), "Development of load transfer model for socketted tubular piles", Proceedings of International Geotechnical Conference, St.Petersburg.

[4]. Butterfield, R. and Banerjee, P.K. (19710, "The problem of pile group and pile cap interaction", Geotechnique, 21(2), $135-142$

[5]. Baragohain, D.N., Raghavan, N. and Chandrasekaran, V.S. (1977), "Interaction of Frames with Pile Foundation", Proceedings of International Symposium on Soil-Structure Interaction, Roorkee, India, January.

[6]. Chamecki, C. (1956), "Structural rigidity in calculating settlement", J. Soil Mech. Found. Div. ASCE, 82(1), 1-19. 
[7]. Chandrasekaran, S.S. and Boominadhan, A. (2010), "Group interaction effects on laterally loaded piles in clay", J.Gete.Geoenviron.Eng ASCE, 136,573-582.

[8]. Chore, H.S and Sawant, V.A. (2002), "Finite element analysis of laterally loaded pile group", Proceedings of Indian Geotechnical Conference(IGC-2002), Allahabad.

[9]. Chore, H.S and Ingle, R.K.(2008a), "Interaction analysis of building frame supported on pile group", Indian Geotech.J., 38(4), 483501 .

[10]. Chore, H.S and Ingle, R.K. and Sawat, V.A. (2009), "Building frame-pile foundation-soil interaction analysis", Interact. Multiscale Mech., 2(4), 397-411.

[11]. Coyle, H.M. and Reese, L.C.(1966),'Load transfer for axially loaded pile in clay”, J.Soil Mech.Foundation Eng. ASCE,92(2),1-26.

[12]. Dasgupta, s., Dutta, S.C. and Bhattacharya, G. (1998), "Effect of soil-structure interaction on building frames on isolated footings", J.Struct. Eng. SERC, 26(2), 129-134.

[13]. Georgiadis, M. and Butterfield, R. (1982), "Laterally loaded pile behavior", J.Geotech.Eng. ASCE, 108, 155-165

[14]. Hain, S.J. and Lee, I.K. (1974), "Rational analysis of raft foundation", J.Geotech.Eng. ASCE, 100(7), 843-860.

[15]. Hazarika, P.J. and Ramasamy, G. (200), "Response of Piles Under Vertical Loading", Indian Geotech.J., 30(2), 73-91.

[16]. Hora, M. (2006), "Non-linear Interaction Analysis of Infilled Building Frame-Soil System", J. Struct. Eng. SERC, 33(4), 309-318.

[17]. Ingle, R.K. and Chore, H.S. (2007), "Soil-Structure Interaction Analysis of Building Frame- an overview", J.Struct.Eng. SERC, 34(5), 201-209.

[18]. IS: 2911-1979(1979), “Code of practice for design and construction of pile foundation”, BIS, New Delhi, India.

\section{Biographies and Photographs}

K. Ramakrishna Reddy was born in 1992. He presently works as Assistant Professor in the Department of Civil engineering at Mother Teresa Institute of Science and Technology. He graduated from Jawaharlal Nehru Technological University, Hyderabad in the year 2013. He received M.Tech degree from Jawaharlal Nehru University, Hyderabad in the year 2015., And He has 3 years of experience in teaching and pursuing Ph.D in Shri Jagadesh prasad Jhabarmal Tibrewala University -Rajasthan, India. Registered Number is $\mathbf{2 0 1 2 1 5 0 1 3}$. His research area includes.

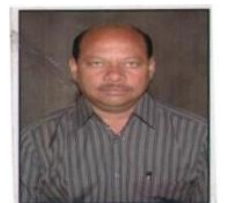

Ch.Ravi was born in 1965 .He presently working as Associate Professor\&HOD in the Department of Civil engineering at Mother Teresa Institute of Science and Technology, He graduated from nagarjuna University, guntur in the year 1992. He recieved M.Tech degree from Jawaharlal nehru University, Kakinada,india. in the year 2013. And He has 15 years of experience in teaching. His research area includes. 